\title{
A PRERROGATIVA DO DIREITO NA CONFERÊNCIA REGIONAL DE EDUCAÇÃO SUPERIOR DA AMÉRICA LATINA E DO CARIBE (CRES) 2018
}

\author{
The prevention of law at the Regional Conference on Higher Education in Latin America \\ and the Caribbean (CRES) 2018
}
La prerrogativa del derecho en la Conferencia Regional de Educación Superior de América Latina y del Caribe (CRES) 2018

\author{
Egeslaine de $\mathrm{Nez}^{*}$ \\ Warley Carlos de Souza**
}

\begin{abstract}
Resumo
A CRES que aconteceu neste mês de junho de 2018, em Córdoba, na Argentina, apresentou como tema: a missão, o sentido e o futuro da Educação Superior. Esse é um dos eventos mais importante do Sistema de Educação Superior latino-americano e consiste numa reunião de dimensão regional organizada em conjunto com o Instituto Internacional para a Educação Superior na América Latina e no Caribe (IESALC) da Organização das Nações Unidas para a Educação, a Ciência e a Cultura (UNESCO). No ano em que a Reforma de Córdoba, que foi um marco para o projeto de universidade, comemora seu centenário, fez-se urgente e necessário analisar o papel da educação superior frente aos desafios sociais propostos num cenário de contextos emergentes. Ressalta-se que a Reforma Universitária de 1918, espalhou-se à época por vários países (Argentina, Peru, Uruguai, Venezuela, México e no Brasil) forjando uma mescla peculiar de autonomia e politização universitária, característica desse movimento. Este artigo objetiva refletir sobre a prerrogativa do direito à Educação Superior que se encontra presente nas discussões da CRES. O procedimento metodológico utilizado neste estudo consistiu na análise textual discursiva. Finalmente, destaca-se que os documentos da conferência regional reafirmam o sentido da educação como bem social, direito humano e responsabilidade do Estado.
\end{abstract}

PALAVRAS-CHAVE: Educação Superior. CRES. Direitos

\begin{abstract}
The CRES, which took place in June 2018 in Córdoba, Argentina, presented as a theme: the mission, meaning and future of Higher Education. This is one of the most important events of the Latin American Higher Education System and consists of a regional meeting organized jointly with the International Institute for Higher Education in Latin America and the Caribbean (IESALC) of the United Nations Educational, Science and Culture (UNESCO). In the year in which the Cordoba Reform, which was a landmark for the university project, celebrates its centenary, it became urgent and necessary to analyze the role of higher education in face of the social challenges proposed in a scenario of emerging contexts. It should be noted that the University Reform of 1918 spread to various countries (Argentina, Peru, Uruguay, Venezuela, Mexico, and Brazil), generating a peculiar mixture of autonomy and university politicization, characteristic of this movement. This article aims to reflect on

\footnotetext{
** Professora da Universidade Federal de Mato Grosso (UFMT), Campus Universitário do Araguaia - Barra do Garças/MT. Doutora em Educação pela Universidade Federal do Rio Grande do Sul (UFRGS). Líder do Grupo de Estudos sobre Universidade (GEU/UNEMAT/UFMT). E-mail: e.denez@ yahoo.com.br

** Professor da Universidade Federal de Mato Grosso (UFMT), Campus Universitário do Araguaia - Barra do Garças/MT. Doutor em Educação pela Universidade de São Paulo (USP). E-mail: warleycarlos@yahoo.com.br
} 
the prerogative of the Right to Higher Education that is present in the discussions of CRES. The methodological procedure used in this study consisted of discursive textual analysis. Finally, it should be noted that the documents of the regional conference reaffirm the meaning of education as a social good, human right and State responsibility.

\section{KEYWORDS: College Education. CRES. Rights}

\section{Resumen:}

La CRES que tuvo lugar en este mes de junio de 2018, en Córdoba, Argentina, presentó como tema: la misión, el sentido y el futuro de la Educación Superior. Este es uno de los eventos más importantes del Sistema de Educación Superior latinoamericano y consiste en una reunión de dimensión regional organizada en conjunto con el Instituto Internacional para la Educación Superior en América Latina y el Caribe (IESALC) de la Organización de las Naciones Unidas para la Educación , la Ciencia y la Cultura (UNESCO). En el año en que la Reforma de Córdoba, que fue un marco para el proyecto de universidad, conmemora su centenario, se hizo urgente y necesario analizar el papel de la educación superior frente a los desafíos sociales propuestos en un escenario de contextos emergentes. Se resalta que la Reforma Universitaria de 1918, se extendió a la época por varios países (Argentina, Perú, Uruguay, Venezuela, México y Brasil) engendrando una mezcla peculiar de autonomía y politización universitaria, característica de ese movimiento. Este artículo objetiva reflexionar sobre la prerrogativa del derecho a la Educación Superior que se encuentra presente en las discusiones de la CRES. El procedimiento metodológico utilizado en este estudio consistió en el análisis textual discursivo. Finalmente, se destaca que los documentos de la conferencia regional reafirman el sentido de la educación como bien social, derecho humano y responsabilidad del Estado.

\section{PALABRAS CLAVE: Educación Universitaria. CRES. Derechos}

\section{INTRODUÇÃO}

Somos excluídos a partir de uma condição real de inclusão da qual não fazemos parte, somos discriminados ou apartados. Talvez até mesmo tornados invisíveis (SPOSATI, 2001, p. 76).

Uma variada gama de realidades, com suas características peculiares e complexas, torna o tratamento dos problemas sociais uma questão que desafia a administração pública. Em seu retrato social, o Brasil revela cores sombrias, em que a exclusão social, a concentração de renda e a desigualdade agravam cada vez mais a pobreza (POCHMANN, et all, 2004). Os elevados níveis de desemprego, fome, miséria, violência, mortalidade infantil, baixos salários e a precariedade da moradia são elementos que traduzem essa desigualdade, impedindo o acesso da população a um patamar mínimo de condições de existência.

Paradoxalmente a essa situação, as políticas públicas deveriam melhorar as condições sociais, como eixo central de um "possível" projeto de desenvolvimento para o país (SOARES, 2001). Assim, a atual situação do cenário nacional apresenta uma realidade complexa e um desafio econômico, social e político, que supõe atender às enormes demandas sociais existentes. Em busca de equacionar esses problemas, essas políticas que constituem, hoje, um dos campos multidisciplinares que mais têm desencadeado o interesse de intelectuais e políticos, tem enfatizado constantemente o âmbito do direito. 
Todavia, para se compreender esse movimento, não se pode ignorar que a toda política pública está subjacente uma intencionalidade. Para isso, é preciso desvelar o conceito de Estado, que segundo Nagel (2001) é a energia vital, que sustenta o capitalismo, oriunda da própria dinâmica da relação social que lhe dá origem. Não só capta e expõe, ao longo do tempo, as transformações operadas na base do trabalho, como processa a viabilização das relações econômicas, comandando a indispensável harmonização entre interesses conflitantes e de uma mesma ou de classes distintas.

Para as teorias críticas, “[...] o Estado Capitalista é um tipo de Estado criado pela burguesia para reproduzir na sua estrutura e funcionamento as características das relações sociais e econômicas que constituem o modo de produção capitalista (BIANCHETTI, 2000, p. 78). Assim, para uma compreensão do que sejam políticas públicas (e sociais), evidencia-se que não são apenas um requisito para a reprodução das condições materiais, mas, também, um elemento fundamental da própria sociedade capitalista (OFFE, 1984).

Assim, na avaliação de políticas implementadas por um governo, elementos de diferentes natureza e determinação são importantes. Segundo Höfling (2001), as políticas públicas se caracterizam como o Estado em ação, implantando um projeto de governo, por meio de programas e de ações voltadas para setores específicos da sociedade. Uma das características-chave das políticas públicas é a universalidade das ações, que devem materializar um direito para todo o público a que se destinam.

Cabe, então, neste sentido ao governo, por meio dos direitos, prover um conjunto de seguranças que reduzam ou previnam riscos e vulnerabilidades sociais, bem como necessidades emergentes ou decorrentes dos problemas sociais. Neste sentido, para Vieira (2009), a conceituação de poder político, não se inspira nos fins do Estado, mas em seu meio particular que é a força. A política social é uma estratégia governamental de intervenção das relações sociais; que normalmente se compõem de planos, de projetos, de programas e de documentos diversos. Se o Estado "é uma organização especial da força, de sua parte, o governo constrói a ordem de cada dia, assegurando e legalizando a dominação" (p. 143).

Os direitos sociais, para Vieira (2009) significam antes de mais nada a consagração jurídica das reivindicações dos trabalhadores. Não significam a consagração de todas as exigências sociais, e sim daquilo que é possível ou necessária no momento. "Adotar bandeiras pertencentes à classe operária, mesmo quando isso configure melhoria nas relações humanas, patenteia a dominação política" (p. 144).

Nascimento, Silva e Algebaile (2002) além de Soares (2001) destacam que ao longo das últimas décadas o modelo de políticas sociais, no Brasil, vem se modificando e passando 
do modelo europeu (pautado nas lutas por direitos universais a partir do princípio da igualdade), para o modelo americano, que propõe a focalização dos direitos sociais (princípio da eqüidade). Vive-se, hoje, então, uma "americanização" da política social brasileira, pois, apesar de formalmente estendida a todos os brasileiros, o alcance dos serviços públicos está sendo reduzido ao atendimento aos mais pobres.

Deste modo, as políticas sociais referem-se a ações que determinam o padrão de proteção social implementado pelo Estado, voltadas, em princípio, para a redistribuição dos benefícios sociais, visando à diminuição das desigualdades estruturais produzidas pelo desenvolvimento socioeconômico excludente do capital.

Este artigo objetiva refletir sobre a prerrogativa do direito à Educação, em especial aqui, à Educação Superior que se encontra presente nas discussões da CRES. Para isso, o texto está organizado em quatro partes: na primeira sinaliza-se o procedimento metodológico; numa segunda parte, apresenta-se a base teórica do direito à educação; em seguida, buscam-se analisar os documentos preparatórios para a conferência regional de educação superior, e, na última parte, as considerações são pontuadas.

\title{
Procedimento metodológico
}

\begin{abstract}
Pesquisar sobre a universidade é debruçar sobre a tarefa intrigante de abordar um objeto de longa trajetória e muitos desafios. Entre eles, o de procurar compreender fenômenos sociais, estruturais, tecnológicos, produtivos e organizacionais que tiveram - e tem - lugar na história do homem, das sociedades e das suas instituições (FIALHO, 2005, p. 15).
\end{abstract}

Todo estudo tem como finalidade a demonstração de um raciocínio lógico. Assume, assim, uma forma dissertativa, que busca comprovar, mediante argumentos, uma constatação. Essa parte do artigo em questão busca identificar o caminho metodológico utilizado nesta investigação. Neste intento, partiu-se de uma concepção de pesquisa que buscasse a problematização da realidade educacional das instituições de educação superior latinoamericanas, não simplesmente como uma ilustração da mente, processada por um imaginário institucionalizado. Pretendeu-se, com isso, que as dificuldades aflorassem, e que os caminhos para sua superação fossem desvelados na partilha das inquietações e angústias (NEZ, 2014).

Assim, ressalta-se que esse estudo se constituiu de pesquisa bibliográfica e documental, e, utilizou-se a análise textual discursiva como abordagem analítica. Para isso, seguiram-se os seguintes passos metodológicos: unitarização (unidades de significado); 
categorização (unidades de significado semelhantes); meta-textos analíticos; e, textos interpretativos (MORAES e GALIAZZI, 2011).

\section{Do direito à educação}

Art. 205. A educação, direito de todos e dever do Estado e da família, será promovida e incentivada com a colaboração da sociedade, visando ao pleno desenvolvimento da pessoa, seu preparo para o exercício da cidadania e sua qualificação para o trabalho (BRASIL, 1988, p. 121).

O estado se desenvolveu tendo como princípio básico o significado de democracia, ou seja, o bem de todos, assim, precisa garantir a igualdade, a liberdade e a fraternidade. Nunca é demais dizer que com ênfase nesses princípios necessita mediar os direitos (conflitos) individuais com os coletivos. Amalgamado a isso, foi preciso eliminar a rudeza dos sujeitos para que pudessem viver juntos, pois, a lógica da contemporaneidade pressupôs que o homem do campo precisa sair e assim foram se formando os grandes aglomerados urbanos, as metrópoles (JAPIASSU, 2007 e SOUZA, 2009). Esse aglomerado legitima e justifica a utilização da palavra direito, pois a convivência de diferentes visões de mundo necessitam de um balizador, que se consubstanciou no direito.

Era necessário abolir o estado de rudeza natural da essência humana. Tal projeto se consolidou na construção das universidades, que objetivam uma formação humana e intelectual em seu interior. Originalmente, esse espaço foi pensado como possibilidade de que todos pudessem por ele passar. Porém, a lógica de produção capitalista objetiva outro caminho, distanciando a grande massa de uma formação intelectual humanizada, movimento esse que objetiva o conhecimento produzido nesse espaço como moeda de ascensão social. Gentili e Mccowan (2010) esclarecem que: “a educação tem lugar privilegiado nos direitos sociais. É ao mesmo tempo determinada e determinante da construção do desenvolvimento social de uma nação soberana" (p. 27).

Remete-se aqui, a Constituição Federal (CF) brasileira que aponta a educação como um direito, um dever e uma obrigação, todavia, acrescenta-se a isso que deve ter qualidade social referenciada ${ }^{\dagger}$. No título II, capítulo I, intitulado de direitos e deveres individuais e

\footnotetext{
$\dagger$ Esse tipo de qualidade esta ligada à distribuição dos recursos materiais e culturais a toda a população, considerando as relações de desigualdades e de poder. Para Nez (2018), isto quer dizer, que a educação deve atender aos mais diversos grupos sociais, para que estes tenham a possibilidade de exercer a cidadania. Segundo Zitkoski (1997) a qualidade socialmente referenciada definitivamente não é aquela que forma quadros de excelência para um novo ciclo de competitividade no mercado econômico, e, que deixa no total abandono (cultural, econômico e político) a maior parte da população.
} 
coletivos, o artigo $5^{\circ}$. aponta que: “Todos são iguais perante a lei, sem distinção de qualquer natureza, garantindo-se aos brasileiros e aos estrangeiros residentes no País a inviolabilidade do direito à vida, à liberdade, à igualdade, à segurança e à propriedade” (p. 12).

Neste sentido, os direitos sociais têm como finalidade permitir que as pessoas disponham dos serviços básicos que garantam um mínimo de condições para a sobrevivência e para a qualidade de vida. E isso, dever ser organicamente realizado pelo Estado que deve proporcionar vida digna ao cidadão por meio desses direitos. Contudo, numa sociedade excludente como a latino-americana nem sempre se consegue garantir os direitos nos âmbitos civis, políticos e sociais.

Para Vieira (2011), a CF de 1988 consagra o estado de direito democrático e cita a política educacional a ser implementada no país. Essa política é amplamente esclarecida, levando em consideração os inúmeros artigos do texto constitucional e seus vínculos com os tratados internacionais anteriores e vigentes no período. Além disso, "[...] reforça a tradição jurídica da educação nos textos constitucionais brasileiros, dando a ela a presunção de constitucionalidade” (p. 9). É notório que a educação é um bem jurídico, individual e coletivo, embora as determinações constitucionais nem sempre sejam cumpridas.

Caminhando nessa direção, a universidade como espaço final de uma formação humanizada intelectual, deve produzir conhecimento e esse deve fundamentalmente voltar-se a comunidade que serviu de base para essa produção. Até porque, a educação é um dos direitos sociais dispostos no capítulo II da CF que se apresenta junto a saúde, a alimentação, o trabalho, a moradia, o lazer, a segurança, a previdência social, a proteção à maternidade e à infância. Caracterizando, deste modo, a necessidade de atendimento ao disposto na legislação no que tange a garantia de condições mínimas de sobrevivência.

Tal princípio somente se concretiza com a autonomia para produção do conhecimento e quando esse conhecimento servir, antes de tudo, para o avanço da sociedade. Esse é um dilema crucial vivenciado pelas universidades atuais, brasileiras ou não. De um lado, o objetivo primordial é o de humanização; e, do outro, a lógica capitalista que advoga que o processo de humanização não é para todos. Situação extremamente complexa para se resolver e avançar para novas proposições frente aos desafios postos, principalmente relacionados aos direitos sociais.

A premissa que aperfeiçoa a universidade moderna como grande produtora de conhecimento mais uma vez lança num dilema fulcral, pois, somente pode ser produzido por sujeitos que, por princípios éticos e morais, consigam realizar uma leitura da realidade usando a racionalidade trazida pela ciência, um sujeito de fato humanizado. Em concordância, 
Menezes (2001, p. 9) assegura que a "instituição universitária é um marco na história da educação mundial, um marco na história do Estado moderno e das nações contemporâneas”. Numa perspectiva dialética, entende-se que a universidade não só é influenciada diretamente pelo tipo de sociedade, como também age sobre ela. E, mesmo sendo fortemente controlada pelo estado, atua refletindo e contribuindo com mudanças, via intelectuais e cientistas, acerca dos interesses decorrentes da relação do estado com a sociedade em cada época.

Diante disso, assevera-se que não existe conhecimento que não seja social e a ele não deva se voltar, nas palavras de Chauí (2003, p. 5) a ênfase principal da universidade moderna foi exatamente a conquista ou o primado da "ideia de autonomia do saber em face da religião e do Estado". Portanto, de uma instituição guiada pelo conhecimento, laica e pensada por sua própria lógica de produção, invenção, descoberta, transmissão e utilidade social ou pública, em contraposição ao dogma e ao misticismo comum da hegemonia da igreja.

É nesse contexto que a universidade se apresenta como uma importante instituição social, cujas mudanças acompanham as transformações sociais, econômicas e políticas. Como instituição social, de cunho republicano e democrático, a relação entre universidade e Estado não pode ser tomada como relação de exterioridade, pois o caráter da universidade é determinado pela presença ou ausência da prática republicana e democrática no Estado.

Com esse olhar, debater a universidade do ponto de vista do direito provavelmente se transforme em redundância, pois, como filha dos princípios republicanos com vistas à garantia da democracia, esse debate nem deveria existir. A esse respeito, Groppo (2011) adverte que estudar a universidade para melhor compreendê-la exige não perder de vista que "é uma criação histórica, estreitamente relacionada com os processos de modernização, os quais incluem a ascensão dos Estados modernos e das nações” (GROPPO, 2011, p. 41).

Essa afirmação conduz a inúmeras reflexões, entre elas leva acento: como falar em direitos no neoliberalismo, que possui como princípio básico, o desemprego em massa e a lei da oferta e da procura? Tais características causam insegurança nos mais fragilizados do ponto de vista social, a saber, os jovens.

\section{A CRES e o direito à educação superior}

De este modo, comenzaba a difundirse y diseminarse un giro conceptual de las políticas de educación superior desde la perspectiva de los derechos, lo cual conlleva, por un lado, una resignificación de las nociones de acceso, expansión y democratización $\mathrm{y}$, por otro, rediseñar y repensar los dispositivos y capacidades estatales para garantizar esa ampliación de derechos. En buena medida, este consenso guió 
las políticas de educación superior de los países de la región durante los últimos 15 años, aunque ciertamente los resultados y alcances fueron muy disímiles (CRES, 2018, p. 26).

Este artigo tece reflexões sobre o a III CRES que aconteceu neste mês de junho de 2018, em Córdoba, na Argentina, apresentando como temática principal: a missão, o sentido e o futuro da Educação Superior. Esse é um dos eventos mais importante do sistema de educação superior latino-americano e consiste numa reunião de dimensão regional organizada pelo Instituto Internacional para a Educação Superior na América Latina e no Caribe (IESALC) da Organização das Nações Unidas para a Educação, a Ciência e a Cultura (UNESCO). Servirá como preparação para a Conferência Mundial da Educação que será realizada em 2021 pela Organização das Nações Unidas (ONU) na França.

A I CRES foi realizada em Havana/Cuba em 1996. Seu maior resultado foi estabelecer e implementar critérios de comparabilidade entre as diversas agências de acreditação de qualidade da Educação Superior na América Latina e no Caribe (UNESCO, 2018). Procurou incrementar os processos de internacionalização, por meio da mobilidade de estudantes e professores, promovendo a integração regional cada vez mais unida no terreno econômico, científico e cultural. No cenário mundial, não teve tanta expressividade, acredita-se que esse fato deve-se ao período vivenciado ou a outros fatores que não puderam ser observados nos documentos.

Já em 2008, em Cartagena das Índias (Colômbia), ocorreu a II CRES que teve grande repercussão e tinha como objetivo construir e divulgar a posição da região acerca da Educação Superior. Serviu como suporte para a Conferência Mundial de Educação Superior (CMES), que foi realizada na França no ano seguinte (UNESCO, 1998). A conferência gerou um dos primeiros documentos que sinalizou a necessidade de criar o Espaço de Encontro Latino-Americano e Caribenho de Educação Superior (ENLACES $\$$ ).

É imprescindível esclarecer que, essa conferência (diferentemente da anterior) recebeu patrocínio da Coordenação de Aperfeiçoamento de Pessoal de Ensino Superior (CAPES) e do Conselho Nacional de Desenvolvimento Científico e Tecnológico (CNPq). O Convênio Andrés Bello (CAB) da Colômbia, a Agência Espanhola de Cooperação Internacional para o Desenvolvimento (AECID), o Centro Extremenho de Estudos e Cooperação com Ibero América (CEXECI) e a Associação Colombiana de Universidades (ASCUN), também o

\footnotetext{
*É uma plataforma de diálogo regional que busca concretizar a cooperação acadêmica entre os países da América Latina, na intenção de criar conhecimentos pertinentes e de qualidade. Essa iniciativa foi gerada para estimular a cooperação entre as diferentes associações, instituições, organizações e entes vinculados à promoção, divulgação e aprimoramento da Educação Superior, fomentando o intercâmbio e a participação destes atores, a fim de propor alianças (ENLACES, 2012).
} 
apoiaram o que ofereceu enorme visibilidade ao encontro. Além disso, houve um amplo processo de preparação que contou com a participação da Organização Continental LatinoAmericana e Caribenha de Estudantes (OCLAE).

Existiu, nesta conferência, uma real possibilidade de participação implementada a partir de múltiplos fóruns e encontros de caráter nacional, sub-regional e regional, cujas conclusões nutriram o evento (movimento que também foi realizado pela III CRES, como será destacado posteriormente). Por outro lado, os estudos coordenados pelo IESALC conduziram à elaboração dos documentos amplamente divulgados que serviram de base para o debate, servindo como aporte teórico.

Aqui aparecem os primeiros elementos balizadores da análise textual discursiva pretendida nesse estudo sobre a questão dos direitos. A unitarização, a categorização, os metatextos analíticos, e, os textos interpretativos do documento final da CRES 2008 identificaram o enquadramento da concepção da Educação Superior como bem público e como ferramenta estratégica de desenvolvimento sustentável e de cooperação interinstitucional. Assim, explicitou a necessidade de um espaço comum do conhecimento e Educação Superior na América Latina e no Caribe, similar ao Espaço Europeu de Ensino Superior (EEES) ${ }^{\S}$, alinhando-se as práticas mundiais.

As instituições e os organismos internacionais, entre eles, inclusive o Banco Mundial $(\mathrm{BM})^{* *}$, estão preocupados com essas questões de cunho social e educacional, pois a ênfase recai sobre o diagnóstico da existência de um bilhão de pobres que precisam de direitos para a sobrevivência. No documento da CRES (2008), que leva em consideração a convicção dos países latino-americanos do valor primordial da Educação Superior e na criação de um futuro melhor, apresenta-se o contexto vivenciado:

Em um mundo onde o conhecimento, a ciência e a tecnologia desempenham um papel de primeira grandeza, o desenvolvimento e o fortalecimento da Educação Superior constituem um elemento imprescindível para o avanço social, a geração de riqueza, o fortalecimento das identidades culturais, a coesão social, a luta contra a pobreza e a fome, a prevenção da mudança climática e a crise energética, assim como para a promoção de uma cultura de paz (p. 3).

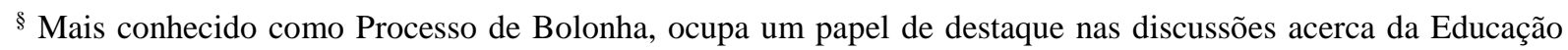
Superior em todo o mundo. Tem como finalidade a convergência dos sistemas de Educação Superior, baseandose em três ciclos (licenciatura, mestrado e doutorado) e busca introduzir um sistema de graus acadêmicos, promovendo a mobilidade dos estudantes, dos professores e dos investigadores, assegurando qualidade aos processos (EUROPA, 2010).

${ }^{* *}$ Fonseca (1998) expõe que o BM busca na educação a sustentação para a sua política de contenção da pobreza, sendo considerado um "ajuste de caridade". Isso consiste em eliminar o analfabetismo e aumentar a eficácia do ensino, melhorando seu rendimento. Justifica, neste sentido, o financiamento com fundos públicos para a Educação, com atenção redobrada à eqüidade, aos pobres, às minorias e a outros grupos desfavorecidos, seguindo, escancaradamente, a cartilha neoliberal.
} 
A questão dos direitos caminha diretamente nesse ponto, o excerto que segue é pertinente para essa reflexão. Na primeira linha do documento oficial da CRES 2008 destacase: “A Educação Superior é um bem público social, um direito humano e universal e um dever do Estado. Esta é a convicção e a base para o papel estratégico que deve assumir nos processos de desenvolvimento sustentável dos países da região" (p. 1 - grifo nosso).

A categorização permitiu evidenciar que há um item exclusivo para tratar da Educação Superior situada como um direito humano e um bem público social. "Os Estados, as sociedades nacionais e as comunidades acadêmicas devem ser os atores que definem os princípios básicos nos quais se fundamenta a formação dos cidadãos e cidadãs, cuidando para que ela seja pertinente e de qualidade" (p. 3). Considerando que o direito à educação é um direito social, proposto na $\mathrm{CF}$ e que esses direitos garantem a vida em sociedade, a participação na riqueza coletiva, e que isso possibilita ao estado democrático reduzir as discrepâncias existentes na sociedade capitalista, a Educação Superior funcionaria como um meio para atingir tal fim.

Ainda no documento, sinaliza-se o caráter de bem público social com que a Educação Superior é tratada, quando se reafirma que seja um direito de todos os cidadãos. "As políticas educacionais nacionais constituem a condição necessária para favorecer o acesso a uma Educação Superior de qualidade, mediante estratégias e ações conseqüentes" (p. 3).

Todavia, é preciso refletir a partir da proposição de "ajustes de caridade" indicados por Fonseca (1998) e na necessidade de trabalhadores para o capital. A CRES 2008 faz um urgente e enfático apelo aos membros das comunidades educativas, aos responsáveis pelas políticas públicas, às organizações internacionais, e aos atores envolvidos nas tarefas educativas universitárias, "[...] para que considerem as demandas e as linhas de ação emanadas do debate ocorrido neste fórum, sobre as prioridades que a Educação Superior deve assumir e partindo de uma clara consciência a respeito das possibilidades e contribuições que ela apresenta para o desenvolvimento da região" (p. 2).

Não se pode deixar de observar uma realidade contraditória, onde a educação, como um direito social, a Superior, no caso da discussão desse estudo, deverá ser afiançada pelo Estado para que a diminuição das desigualdades sociais seja favorecida. Contudo, as ideias mundiais têm instalado um discurso na privatização na América Latina. No Brasil, especificamente, pensar em privatizar as universidades públicas é inaceitável, visto que é um país de tamanhas desproporções (geográficas e sociais). Isso significaria, elitizar cada vez mais o acesso às instituições e promover a continuidade de uma sociedade injusta e desigual. 
No momento atual, em que se implementa de forma brutal um Estado mínimo, reduzindo o investimento público em direitos sociais, como vem acontecendo sorrateiramente, privatizar as universidades significaria acabar com uma das poucas oportunidades de mobilidade social dos mais jovens, de elevação do nível de escolaridade e de conhecimento da população em geral. É nítida a intenção do governo federal em reduzir o papel do Estado e ampliar a atuação da iniciativa privada em diversos setores da Educação.

Conforme já citado, em 2018 aconteceu a III CRES. O evento é realizado a cada dez anos, nessa edição foram debatidos critérios para formular propostas e alinhamentos de ação com a finalidade de consolidar a Educação Superior como um bem social, direito humano e universal, e responsabilidade dos Estados. Contou com a participação de gestores, pesquisadores e estudantes que discutiram sete eixos temáticos que resultaram em estratégias conjuntas que deverão ser adotadas no sentido de garantir o acesso à universidade.

Antes da III Conferência, foram previstas instâncias de debate participativo (fóruns e eventos regionais) sobre o estado atual da Educação Superior (pontos fortes/fracos, história e evolução. Destacaram-se as propostas de melhorias que são desejadas para a próxima década, que comporão a agenda Educação 2030 da UNESCO. Além disso, as conclusões da CRES 2018 integrarão a pauta preparatória, que os países da América Latina e do Caribe, levarão à Conferência Mundial de Educação Superior, a ser realizada em 2019.

Um dos documentos gerado num dos colóquios regionais, intitulado "Balance de la Declaración de Cartagena y aportes para la CRES 2018", que foi realizado na Universidad Nacional de las Artes de la Ciudad de Buenos Aires, em 2017, afirma a Educação Superior como um bem público e social, direito humano e universal, além de ser dever do Estado. "Esta es la convicción y la base para el papel estratégico que debe jugar en los processos de desarrollo sustentable de los países de la región" (CRES, 2017, p. 1).

Considera-se a necessidade de: "Que los gobiernos asuman su responsabilidad por la garantía de la educación superior como bien público y social, derecho humano y desarrollar políticas públicas acordes, asegurando su financiamiento" (p. 1). Todavia, o ajuste fiscal leva a uma redução dos investimentos em uma área estratégica como a Educação Superior, impactando severamente na garantia do direito ao ensino público, gratuito e de qualidade. Mesmo com as garantias estabelecidas nos artigos 205 e 206 da CF, que determinam os princípios a igualdade das condições de acesso e permanência na escola e a gratuidade do ensino em estabelecimentos oficiais, a privatização vem encontrando fôlego.

Outro elemento que grande relevo nos meta-textos analíticos é de que a III Conferência explicita a "[...] afirmación de que el conocimiento es un derecho humano 
universal y un bien público y social, por lo cual el Estado debe garantizar su democratización [...] No solo debe existir más universidad en la sociedad sino también más sociedad en la universidad (CRES, 2017, p. 2).

Esse espaço pode-se concretizar num diálogo permanente de fortalecimento da Educação Superior latino-americana, visto que há uma necessidade de discussão contínua devido a complexidade do momento vivenciado. Numa análise detalhada dos textos interpretativos, destaca-se que o documento produzido nesse colóquio regional reverbera o valor social da Educação Superior e sua capacidade transformadora para alcançar sociedades sustentáveis e integradoras, que possam contribuir para a democracia e a cidadania.

Além desses elementos apontados nos textos interpretativos, sinaliza-se também que o debate realizado foi acerca do sistema educativo, a diversidade cultural, a internacionalização da educação, a integração regional, a pesquisa científica e tecnológica, entre outras temáticas. "En este contexto, el impulso a procesos de internacionalización con integración regional y desde una perspectiva de derechos tiene como principal y ambicioso objetivo contribuir a la convergencia de un proyecto común de universidad latinoamericano y caribeño" (CRES, 2017, p. 4).

\section{CONSIDERAÇÕES FINAIS}

Esperemos, apesar de tudo, que haja alguns leitores que não tenho medo das verdades, mesmo desagradáveis, e que reconheçam o rigor da nossa análise e o realismo das nossas recomendações (KOURGANOFF, 1989, p. 14 - grifos do autor).

O processo de definição de políticas sociais reflete os conflitos de interesses, os arranjos feitos nas esferas de poder que perpassam as instituições do Estado e da sociedade como um todo. Neves (1999) considera que: "têm sua gênese e dinâmica determinadas pelas mudanças qualitativas ocorridas na organização da produção e nas relações de poder que impulsionaram a definição das estratégias econômicas e político-sociais do Estado nas sociedades capitalistas" [...] (p. 12).

Neste sentido, deve-se defender, aqui, o papel primordial das políticas sociais na resolução dos problemas agravados pelos ajustes, que hoje afligem parcela considerável da população latino-americana, e, da brasileira, em especial. Como as demais políticas sociais, a política educacional envolve um amplo conjunto de agentes sociais. Ela se expressa, sobretudo, por meio de iniciativas direta ou indiretamente promovidas pelo poder público. 
O que se busca para um país como o Brasil, com uma desigualdade social gigante, é uma sociedade em que a inclusão seja o aporte básico para caracterizar-se uma política social. Não se pode dizer "inclusão de todos", porque o alcance da totalidade é um lugar em contínua construção. Isto quer dizer, a inclusão social como processo histórico é um contínuo e não um lugar posto e estável. Para Sposati (2001), trata-se de um processo relacional, portanto, é mutável, é dialético.

Assim, no ano em que a Reforma de Córdoba, que foi um marco para o projeto de universidade, comemora seu centenário, fez-se urgente e necessário analisar o papel da educação superior frente aos desafios sociais propostos num cenário de contextos emergentes de concretização de direitos.

Efetivamente tais políticas devem fortalecer a proteção social dos mais vulneráveis, os jovens, pois, o mundo do trabalho na atualidade apregoa a necessidade de uma escolarização elevada. Em contrapartida, pouco se tem feito para garantir uma efetiva implementação de um processo inclusivo para aliviar os conflitos relacionados a vulnerabilidade social.

A distância entre as solicitações do mundo do trabalho e a capacidade de proteção social constroem um estado de sofrimento ético-político, que nas palavras de Sawaia (1998), "as diferentes formas de mutilação da vítima, que diminuem a potência de ação na vivência da tensão entre resistência e submissão, vividos como sentimento e necessidade do eu" (p. 6).

Nessa direção, a formação humana é fundamental (educação) para ruptura total com esse processo, isso basicamente perpassa pela formação escolar, conhecimento organizado e sistematizado. Constitui-se, dessa forma, uma das possibilidades de compreensão das desigualdades oriundas da precarização de acesso aos bens socialmente construídos.

Sawaia (1995) explicita que, "conhecimento, ação e afetividade são elementos de um mesmo processo, o de orientar a relação homem com o mundo e com o outro" (p. 164). Destarte, debater por meio de políticas públicas a equidade e a garantia de uma educação de fato e de direito para todos, que garanta a qualidade social é papel fundamental da universidade, dos organismos internacionais e da população em geral.

A CRES 2018 que aconteceu sob o primeiro centenário da Reforma Universitária de 1918 ocorrida em Córdoba, foi uma boa oportunidade de reforçar esses direitos e honrar a luta daqueles jovens que fizeram um grande movimento de resistência. Assim, participar da III Conferência com o compromisso e a decisão impostergável de construir um futuro de prosperidade e bem-estar para os países da América Latina e o Caribe, foi objetivo ímpar que moveu o processo e que se observa presente em todos os documentos analisados. 


\section{REFERÊNCIAS}

BIANCHETTI, R. G. Modelo neoliberal e políticas educacionais. 3. ed. São Paulo: Cortez, 2000.

BRASIL. Constituição da República Federativa do Brasil 1988. São Paulo: Saraiva, 2007.

CHAUI, M. A universidade pública sob nova perspectiva. Revista brasileira de educação, São Paulo, n. 24, set.-dez., p. 5-15, 2003.

CRES. Declaração da conferência regional de educação superior da América Latina e do Caribe 2008. Disponível em:

<http://unesdoc.unesco.org/images/0013/001344/134422por.pdf>. Acesso em: 20 jan. 2012.

CRES. Declaração de Buenos Aires. Disponível em:

$<$ http://iec.conadu.org.ar/noticias/coloquio-regional-balance-de-la-declaracin-de-cartagena-yaportes-para-la-cres-2018_103>. Acesso em: 14 nov. 2017.

ENLACES. Disponível em:

<http://iesalc.unesco.org.ve/index.php?option=com_content $\&$ view=frontpage \&Itemid=303>. Acesso em: 03 nov. 2012.

EUROPA. Disponível em:

<http://europa.eu/legislation_summaries/education_training_youth/lifelong_learning/c11088_ pt.htm>. Acesso em: 13 set. 2010.

FIALHO, N. H. Universidade multicampi. Campinas: Autores Associados, 2005.

FONSECA, M. O financiamento do banco mundial à educação brasileira: vinte anos de cooperação internacional. In.: DE TOMMASI, L.; WARDE, M. J.; HADAD, S. (orgs.) $O$ banco mundial e as políticas educacionais. 2. ed. São Paulo: Cortez, 1998.

GENTILI, P.; MCCOWAN, T. Reinventar a escola pública: política educacional para um novo Brasil. 2. ed. Petrópolis: Vozes, 2010.

GROPPO, L. A. Juventude: ensaios sobre sociologia e história das juventudes modernas. Rio de Janeiro: DIFEL, 2011.

HOFLING, E. M. Estado e políticas (públicas) sociais. Caderno Cedes. Campinas, v. 21, n. 55, nov. 2001.

JAPIASSU, H. Como nasceu a ciência moderna: e as razões da filosofia. Rio de Janeiro: Imago, 2007.

KOURGANOFF, V. A face oculta da universidade. Porto: Lello \& Irmão, 1989.

NAGEL, L. H. O estado brasileiro e as políticas educacionais a partir dos anos 80. In.:

HIDALGO, A. M.; SILVA, I. L. (orgs.) Educação e estado: as mudanças nos sistemas de ensino do Brasil e do Paraná na década de 90. Londrina: UEL, 2001.

MENEZES, L. C. Universidade sitiada: a ameaça de liquidação da universidade brasileira. São Paulo: Perseu Abramo, 2001. 
MORAES, R.; GALIAZZI, M. C. Análise textual discursiva. Ijuí: Unijuí, 2011.

NASCIMENTO, A.; SILVA, A. F.; ALGEBAILE, M. E. B. Estado, mercado e trabalho: neoliberalismo e políticas sociais. NEVES, L. M. W. (org.) O empresariamento da educação: novos contornos do ensino superior no Brasil dos anos 1990. São Paulo: Xamã, 2002.

NEVES, L. M. W. Educação e política no Brasil de hoje. 2. ed. São Paulo: Cortez, 1999.

NEZ, E. Conselho municipal de educação (CME): desvelando o conceito de qualidade socialmente referenciada. Humanidades \& inovação, v.5, 2018.

Em busca da consolidação da pesquisa e da pós-graduação numa universidade estadual: a construção de redes de pesquisa. Tese de Doutorado em Educação da Universidade Federal do Rio Grande do Sul (UFRGS), Porto Alegre, 2014.

OFFE, C. Problemas estruturais do estado capitalista. Rio de Janeiro: Tempo Brasileiro, 1984.

POCHMANN, M. et all. (orgs.). A exclusão no mundo. São Paulo: Cortez, 2004.

SAWAIA. B. B. Configuração psicossocial do sofrimento ético-político no processo de inserção social pela exclusão. São Paulo, 1998. (mimeo).

Dimensão ético-afetiva do adoecer da classe trabalhadora. LANE, S. T. M; SAWAIA, B. B. (orgs.) Novas veredas da psicologia social. São Paulo:

Brasiliense/EDUC,1995.

SOARES, L. T. R. Ajuste neoliberal e desajuste social na América Latina. Petrópolis: Vozes, 2001.

SOUZA, W. C. Transtorno do déficit de atenção com hiperatividade: um caso clínico ou invenção pedagógica? Tese de Doutorado em Educação da Universidade de São Paulo (USP), São Paulo, 2009.

SPOSATI, A. A inclusão social e o programa de renda mínima. Serviço social e sociedade. São Paulo: Cortez, n. 66, a. XXII, jul. 2001.

UNESCO. Declaración mundial sobre la educación superior en el siglo XXI: visión y acción. Paris: Unesco, 1998.

Disponível em: 〈www.unesco.org.ve〉. Acesso em: 20 maio 2018.

VIEIRA, E. Os direitos e a política social. 3. ed. São Paulo: Cortez, 2009. nov./2001.

A política e as bases do direito educacional. Cadernos Cedes. A. XXI, n. 55,

Recebido em: 14/02/2018

Aceito em: 08/04/2018 